\title{
CLASSIFICATION OF GEOMETRY FOR DEPLOYABLE STRUCTURES USED FOR INNOVATION: DESIGN OF NEW SURFACES WITH SCISSOR 2 BAR, AND FORM GENERATION METHOD OF RELATIVE RATIOS
}

\author{
E. RIVAS ADROVER \\ Department of Architecture, University of Cambridge, Britain.
}

\begin{abstract}
Deployable structures can expand and/or contract due to their geometrical, material and mechanical properties. This research proposes a classification of geometry for deployable structures. This classification system applied to structures made with scissor 2 bar can lead to architectural innovation. This is demonstrated in the case study of a new design for surfaces based on scissors 2 bar. Through this case study a form generation method of relative ratios is formulated that can be applied to infinite geometrical arrangements.

This geometry classification is an attempt to seek further understanding of the subject of deployable structures. In order to gain a comprehensive understanding of this field, different ways of ordering information are being considered.

Keywords: 2 bar, classification, database, deployable, design, geometry, innovation, scissor, surface.
\end{abstract}

\section{INTRODUCTION}

Exactly 20 years ago in 1996, a classification of deployable structures was proposed by Félix Escrig Pallarés based on applications and published in the second of these series of conferences, MARAS II [1]. Another classification is that of A. Hanaor and R. Levy, published in 2001 [2], for deployable structures capable of creating an enclosure, based on their morphology and their kinematic behaviour. The author of this paper also proposed a classification for deployable structures based on materials that was published in 2015 [3].

The following classification and design case study use as a foundation the subject of advanced descriptive geometry, which is an active field of study of architecture and engineering in countries such as Spain, and has as its objective the determination of forms in space and the different ways of projecting those in a plane.

\section{CLASSIFICATION OF GEOMETRY FOR DEPLOYABLE STRUCTURES}

The following is a classification of the observed phenomena of deployable structures: its geometry. It explains the geometry achieved by the deployment, and the geometry of its morphology. In order to explain what it is meant by this, let us examine these two very different projects: the cover for San Pablo Swimming Pool in Seville by Escrig et al. [4], and a project by Angust Brown named 'Loose Geometry: Memory Joints' [5]. The first is made with scissors and the later with air cells, but their underlying geometrical arrangement is identical. In both, the geometry achieved by the deployment is spherical, and the geometry of the morphology is achieved by repeating the intersection of two lines which makes a grid of squares, also denominated two-way grid (Fig. 1).

The following geometries of lines, solids and surfaces can be used as the geometry achieved by the deployment and the geometry of the morphology (Fig. 2). 


\section{Geometry of morphology}

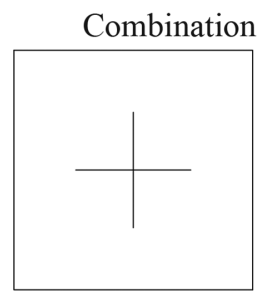

Geometry achieved by the deployment

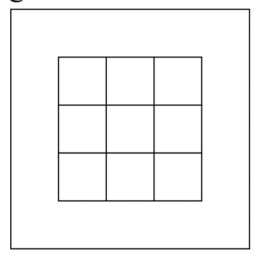
Spherical surface
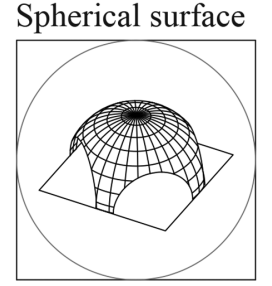

Figure 1: Common geometry of a scissor and inflatable type.

\subsection{Lines}

From a one-dimensional element, a line can curve and extend into the two-dimensional space where there are infinite curved geometries such as parabolas, ellipses, hyperbolas, and infinite curves with arbitrary geometry. A line can also extend in three-dimensional space with formations such as a helix, spiral helix or a string helix or infinite arbitrary curves. Geometrical formations can also be formed by combinations of lines of any of the above.

Case studies that are formed by combinations of degree 1 and degree 2 lines are for instance the distaff [1] and the pantographic deployable structure with a mesh reflector by You and Pellegrino [6].

\subsection{Solids}

There are infinite regular formations of solids such as polyhedrons and pyramids. There can also be infinite solids with curved geometries such as paraboloids, ellipsoids and tori. There are also infinite solids with arbitrary geometry. There can also be infinite combinations and intersections of solids.

Examples that deploy into solids are the icosahedron by Escrig [7], the Hoberman sphere and the 'Blob' by Jensen and Pellegrino [8].

\subsection{Surfaces}

Surfaces are a prolific geometrical group since they allow for the deployment of enclosures, which can be used for a variety of applications including architectural applications.

There are infinite possibilities for making surfaces but the most commonly used are flat surfaces, cylindrical surfaces, vaults with regular or arbitrary geometry, barrel vaults, conical surfaces, spherical surfaces, anticlastic and synclastic surfaces, hyperbolic paraboloids and infinite surfaces with arbitrary geometry.

A paper that illustrates an indefinite growth of surfaces is 'Geometric models of expandable structures' by Sanchez-Cuenca [9]. Escrig developed structures based on scissor 2 bar that deploy into flat, vaulted and spherical surfaces [7].

\section{ON ORDERING INFORMATION}

There is an increasing interest from the design and scientific communities on complex geometries and deployable structures. However, publications are scattered in many different sources and fields, causing problems to present and future generations. Classifications 


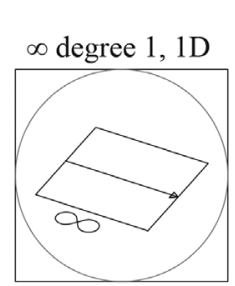

$\infty$ degree $1,2 \mathrm{D}$

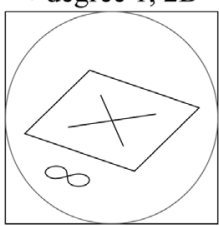

$\infty$ polyhedrons
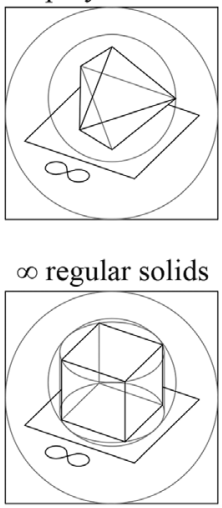

$\infty$ flat, 2D

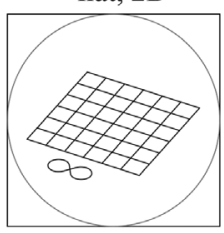

$\infty$ anticlastic

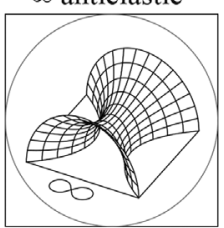

\section{Lines}
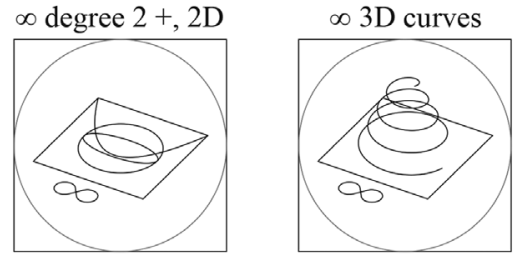

Combination of lines

$\infty$ degree $1 \& 2+, 2 \mathrm{D} \infty$ degree $1 \& 2+, 3 \mathrm{D}$

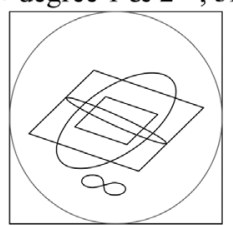

$\infty$ arbitrary $2 \mathrm{D}, 3 \mathrm{D}$

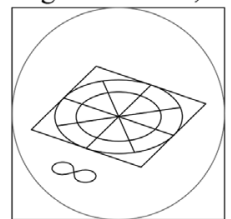

\section{Solids}
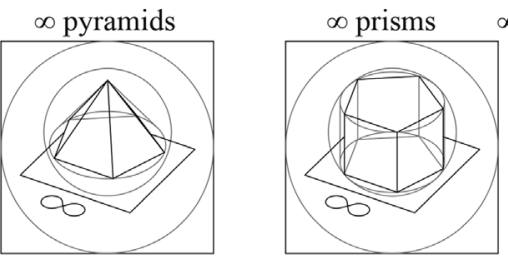

$\infty$ arbitrary prisms, $2 \mathrm{D} \mathrm{c}$.
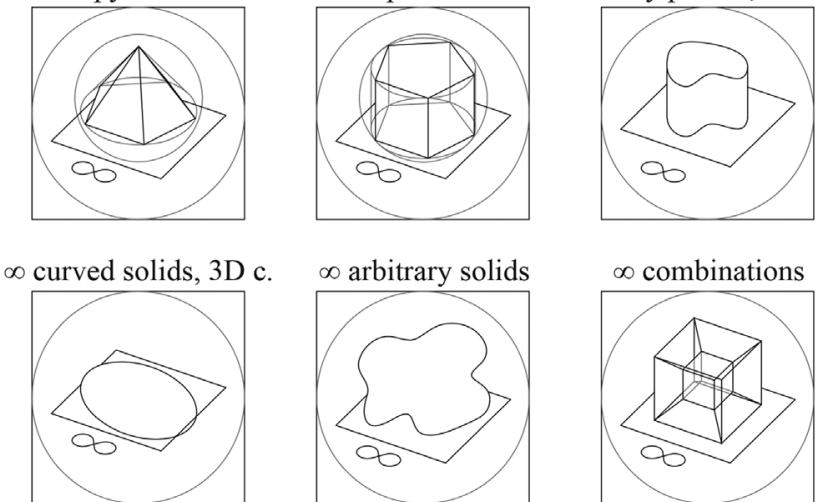

Surfaces

$\infty$ vaults, $2 \mathrm{D}$ c. $\infty$ arbitrary vaults, $2 \mathrm{D}$ c.
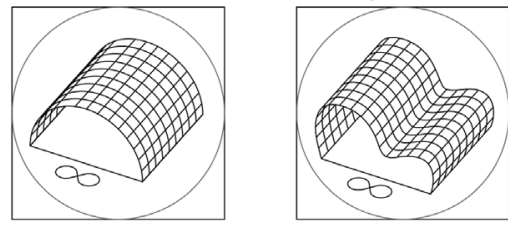

$3 \mathrm{D}$ curvature

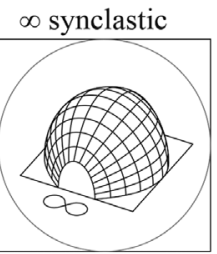

$\infty$ hyperbolic paraboloids

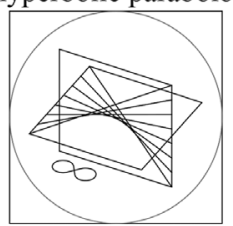

$\infty$ spherical, 3D c.
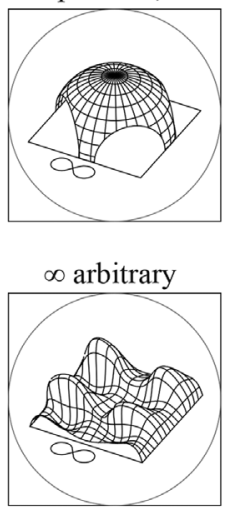

Figure 2: Table of classification of geometry for deployable structures. 
can therefore be valuable and can vary greatly depending on the criteria chosen and the different ways of ordering the same information, such as a table, a tree diagram a matrix or a database.

For instance a tree diagram for the scissor type could visualize how from the Mesopotamian foldable stool from 2400 B.C [10], to the first unprecedented creation of a surface by Emilio Pérez Piñero [11] and Escrig's astounding contribution [12], to the present day there has been an incremental growth.

The format of a matrix was explored by the author, which was an extension of the geometry classification here provided and applied to the scissor 2 bar type. On the axis $\mathrm{x}$ were geometries achieved by the deployment, and on the axis y the options for the geometry of the morphology combined with the scissor types. Since there were thousands of potential scenarios it proved too difficult to control. However, this method displays how combining geometrical parameters can lead to innovation, an example being the new surface proposed here.

A database would allow to vary the criteria in the search and it could therefore contain all the previous classifications that have been done and other angles that have yet not been seen. Due to this versatility, this is going to be a focus of future research. A precedent of how a database can throw new light onto a subject is the materials database for industrial design by Ashby [13].

\section{APPLICATION OF THE GEOMETRY CLASSIFICATION FOR INNOVATION: DESIGN OF SURFACE MADE WITH SCISSOR 2 BAR}

So far surfaces with scissor 2 bar (with the units not coplanar to the surface) have been done by grids that make triangles or squares (Fig. 3) also known as 2 and 3 way grids, concepts developed by Escrig [7], and 4 way grids [14].
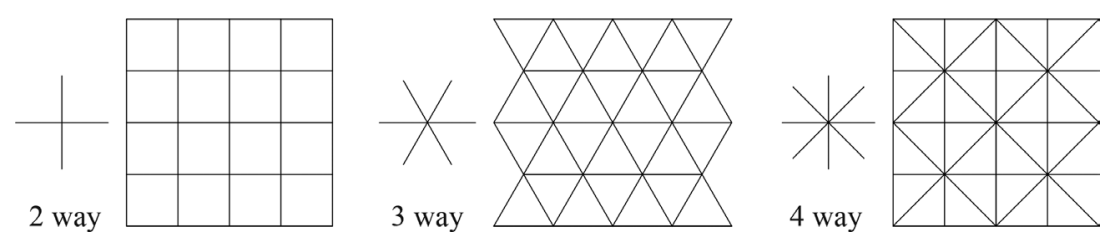

Figure 3: 2, 3 and 4 way grids used for making surfaces with scissor 2 bar.

\subsection{Surface made with combination of degree 1 lines and form generation method of relative ratios}

The following surface has been developed using geometrical relationships and spatial calculations based on descriptive geometry. By intersecting six straight lines at equal angles four times, one obtains a square with multidirectional degree 1 lines, which contains what resembles an octagon in the centre. The concept here is to apply scissor 2 bar translational regular units to this combination of lines in order to generate a flat surface (Fig. 4). This geometry is made of eight S1 segments and four S2 segments (Fig. 5). The first step is to identify the smaller sub segment in S1 segment, A. This smaller sub segment A will be the length in 


\section{Geometry of morphology}

Translational units
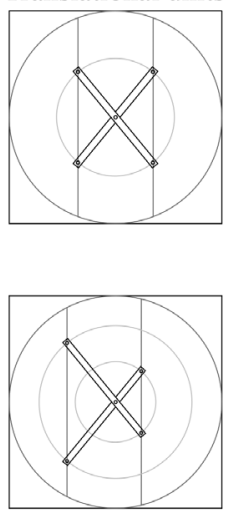

Combination of degree 1 lines
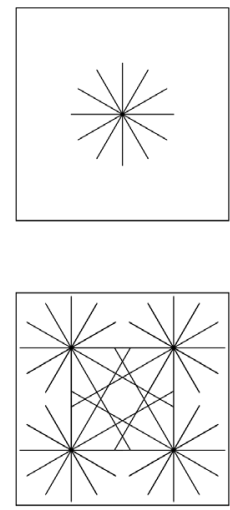

Geometry achieved by the deployment

Flat surface

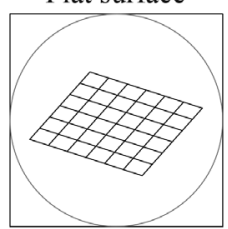

Units perpendicular to surface

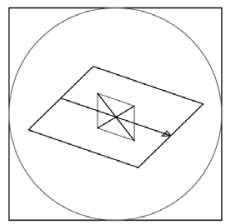

Figure 4: Concept for generation of surface applied to scissor 2 bar.

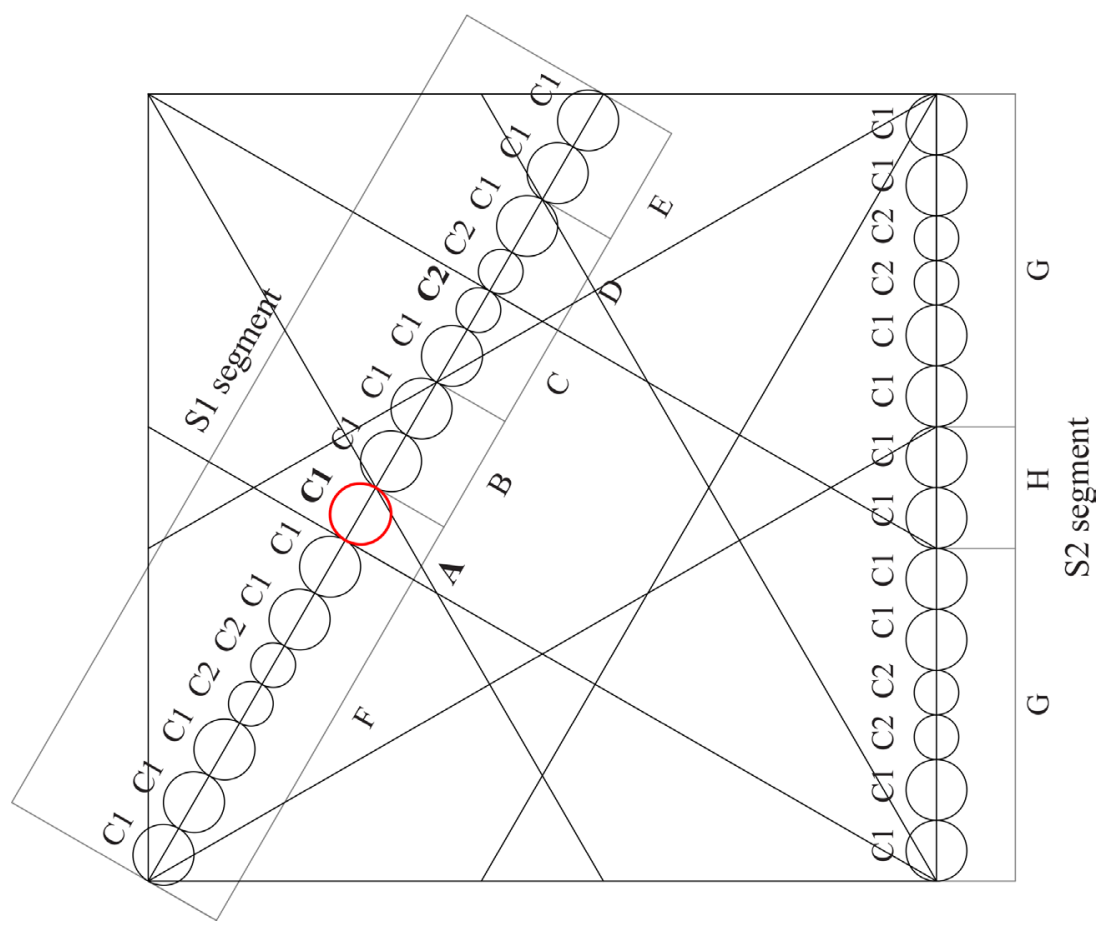

Figure 5: Applying ratios $\mathrm{C} 1$ and $\mathrm{C} 2$ to all sub segments in segments $\mathrm{S} 1$ and S2.

which to fit a scissor unit and will be denominated $\mathrm{C} 1$. The distance $\mathrm{C} 1$ is then transferred to all other sub segments. By doing this a second distance, $\mathrm{C} 2$, is established. The scissor units in $\mathrm{C} 2$ will be the same as in $\mathrm{C} 1$ but cut at one end. Both distances for scissor units $\mathrm{C} 1$ and $\mathrm{C} 2$ are also used to establish the ratios in S2 segment (Figs 5 and 6). 
S1 segment

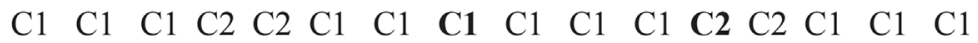

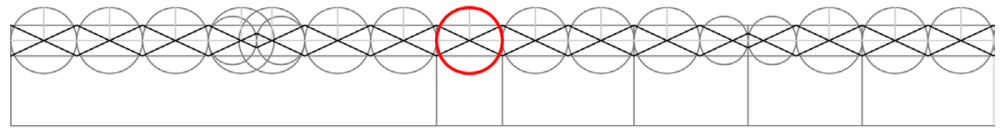

$\begin{array}{lllllll}\mathrm{F} & \mathrm{A} & \mathrm{B} & \mathrm{C} & \mathrm{D} & \mathrm{E}\end{array}$

S2 segment

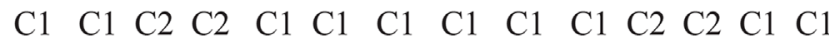

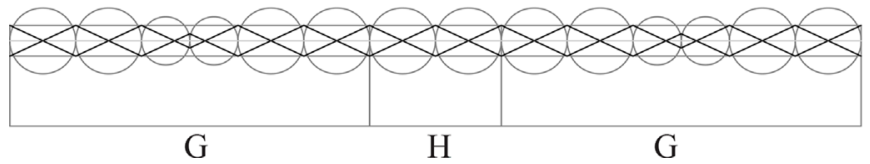

Figure 6: Applying scissor units to ratios $\mathrm{C} 1$ and $\mathrm{C} 2$ in segments $\mathrm{S} 1$ and S2.

The geometry of the segments $\mathrm{S} 1$ and $\mathrm{S} 2$, and their subs segments is defined by the relative ratios of $\mathrm{C} 1$ and $\mathrm{C} 2$, which are described by the following geometrical relationships described by the set of equations in (1)-(3):

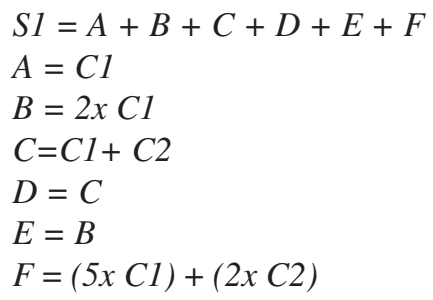

$$
\begin{aligned}
& S 2=h+(2 \times G) \\
& H=2 x C 1 \\
& G=(4 x C 1)+(2 \times C 2) \\
& H=b \\
& G=F-C 1 \\
& G=C+D+E
\end{aligned}
$$

When transferring S1 segments to their three-dimensional position (Fig. 7), in nodes 2, 3 and 5 the scissor units end nodes do coincide, but node 1 intersects node 4 and the end nodes

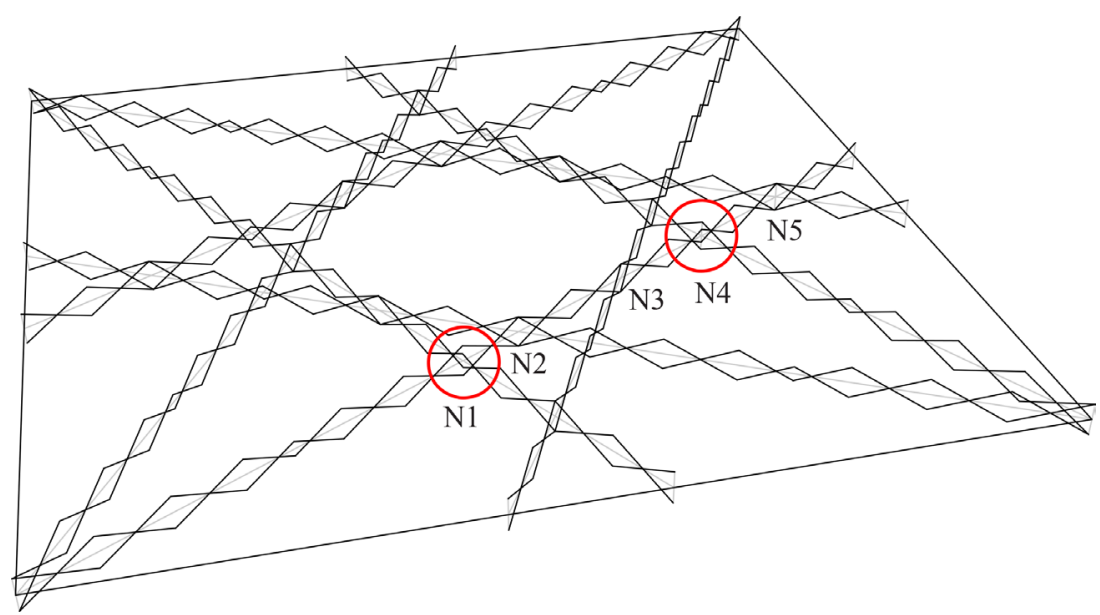

Figure 7: Identifying intersecting nodes that do not match: N1 and N4 nodes. 
do not coincide. In order to resolve this, all $\mathrm{C} 1$ and $\mathrm{C} 2$ ratios are divided in half. This allows for the smaller scissor units at node 4 to be separated and brought inside the sub segments (Fig. 8, top).

The resulting structure (Fig. 9) could be reinforced in the areas where the pantographs have a long span by adding extra members.

A spherical deployment is investigated for this surface with translational non-regular units; therefore, all the unit lines will be perpendicular to a horizontal plane. When transferring the relative ratios to a curve belonging to a circle and placing them in their three-dimensional position, the pantographic arches and the scissors end nodes intersect perfectly at node 2 . However, nodes 3 and 5 show that while the pantographic arches do intersect, the scissor unit lines do not. In order to resolve this problem, the geometry is established from the nodes that

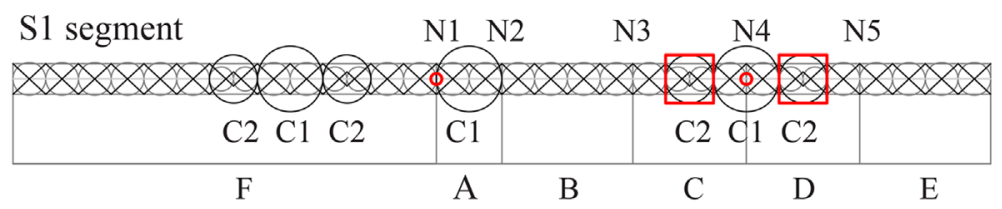

S2 segment

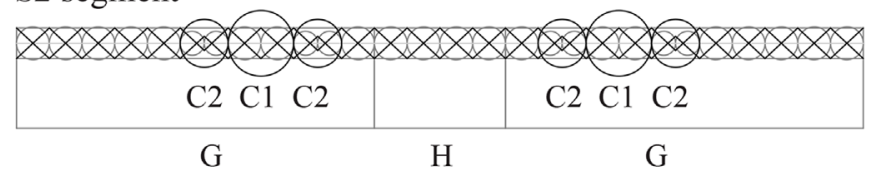

Figure 8: Halfing ratios $\mathrm{C} 1$ and $\mathrm{C} 2$ to adjust $\mathrm{N} 1$ and $\mathrm{N} 4$ nodes.

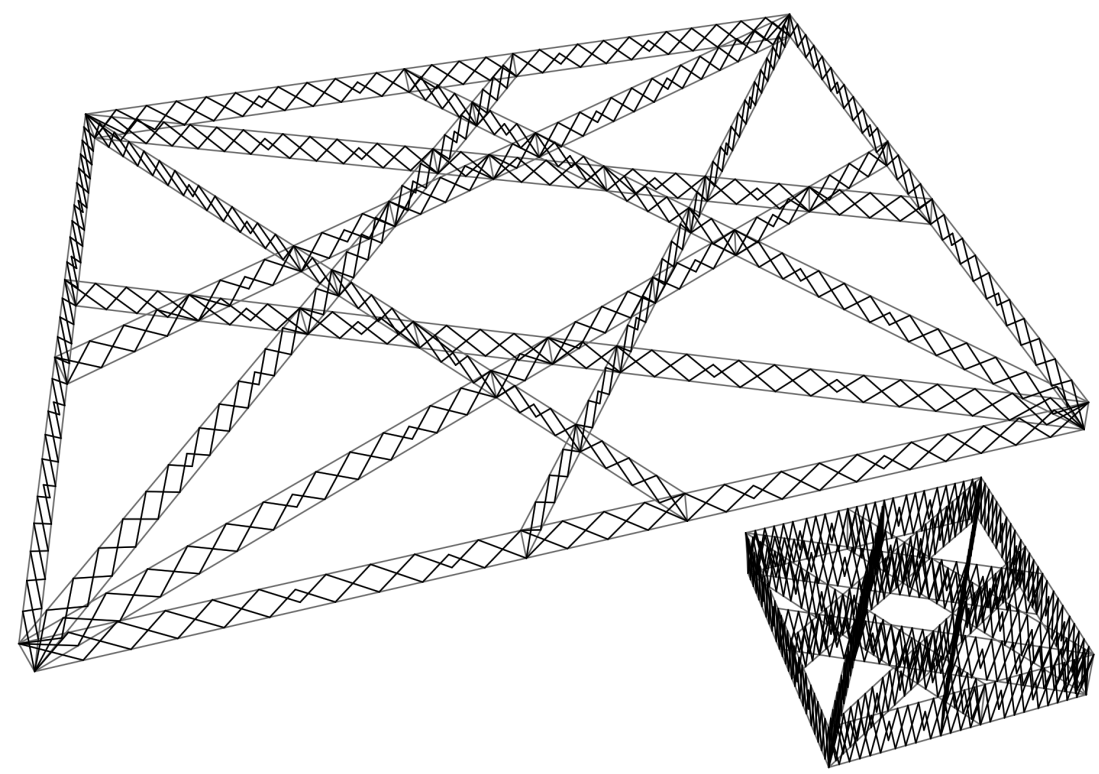

Figure 9: Square module with all nodes matching; deployed and packaged states. 


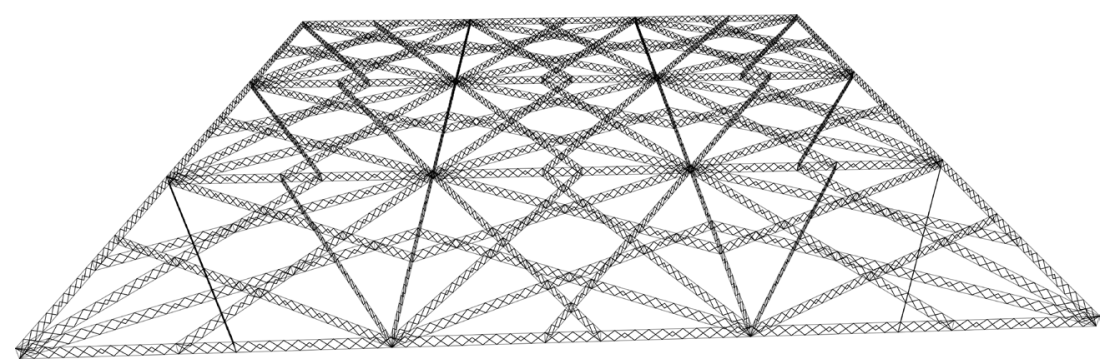

Figure 10: Replication of square module, 6 way grid.

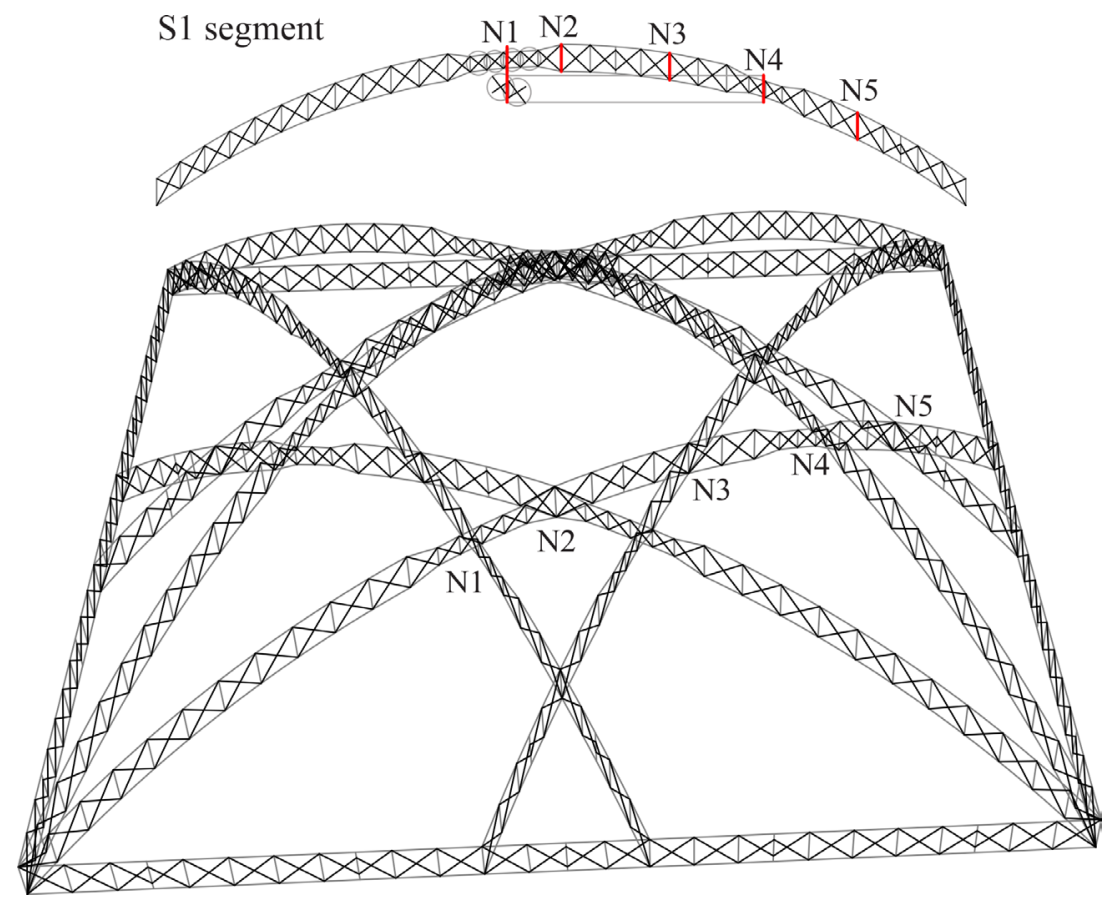

Figure 11: Spherical deployment. First solution to problem in N1 and N4 nodes.

mark the intersections, node 3 and node 5 , and the smaller scissor units are placed inside the sub segments (Figs 11 and 12).

However there is one more problem to solve in node 1 and node 4 . While in the deployed position these pantographic arches do not intersect, while the structure contracts these would clash. Two different solutions are investigated to solve this problem. Figure 11 shows a solution by which the scissor units are reduced in size in both node $\mathrm{N} 1$ and node $\mathrm{N} 4$. The second solution is to lower down the height of node N1 to coincide with N4 and to adjust the scissor units from these intersections (Fig. 12). With this method a peculiar geometry is generated that allows for all nodes to intersect, making the structure more structurally stable. In sub segments A and C 


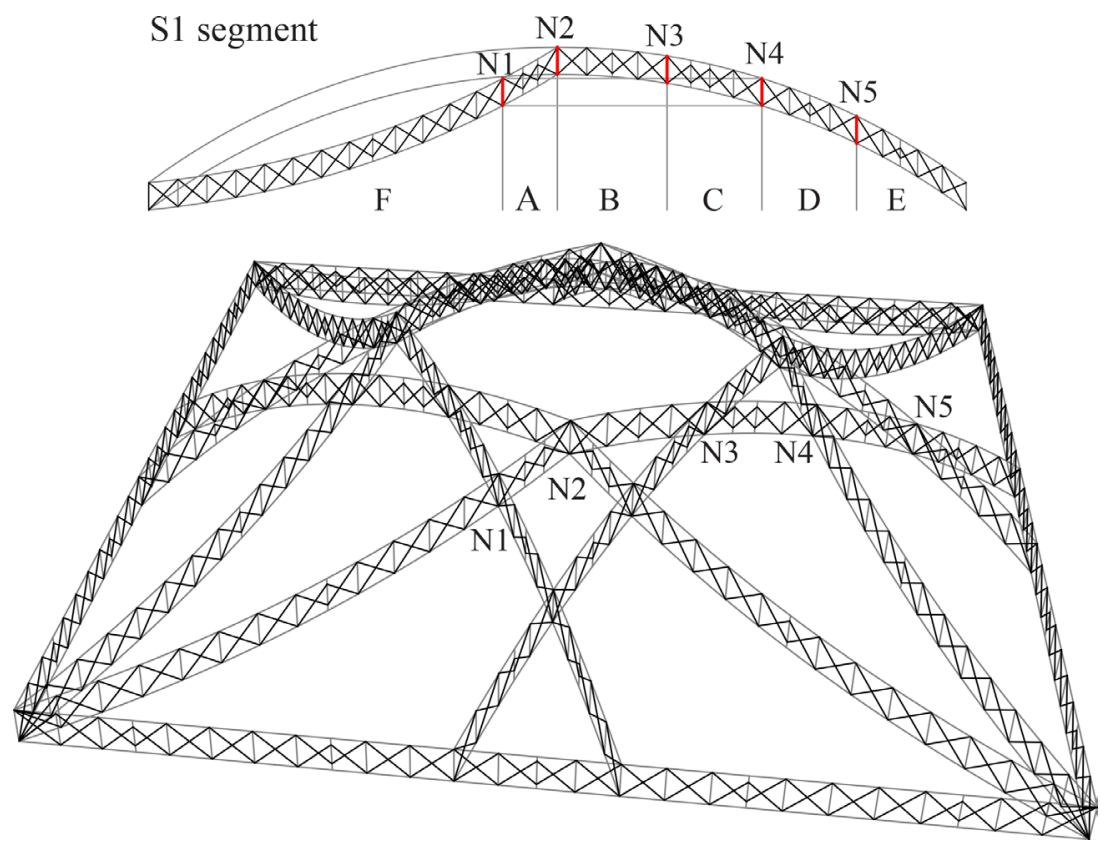

Figure 12: Spherical deployment. Second solution to problem in N1 and N4 nodes.

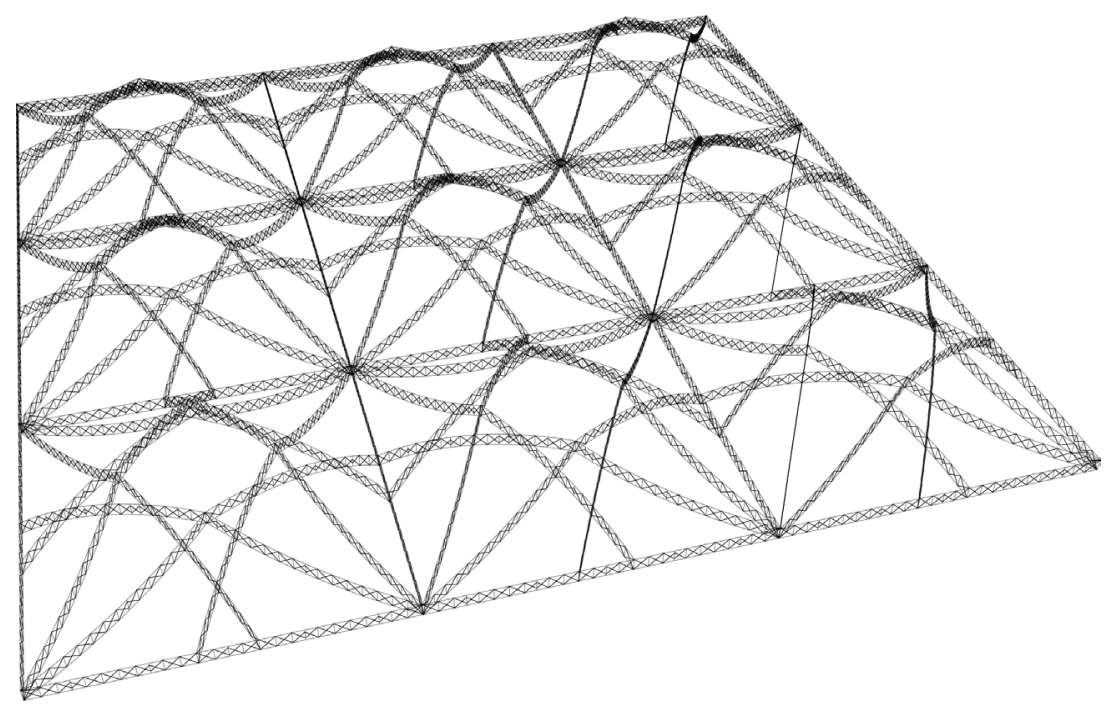

Figure 13: Replication of square modules with spherical deployment.

(Fig. 12, top) the small ratio for a scissor unit has been further subdivided to improve the mobility of the structure; this concept could be applied to the smaller scissor units in sub segment E.

The resultant square module can be replicated in various ways (Figs 13 and 14). 


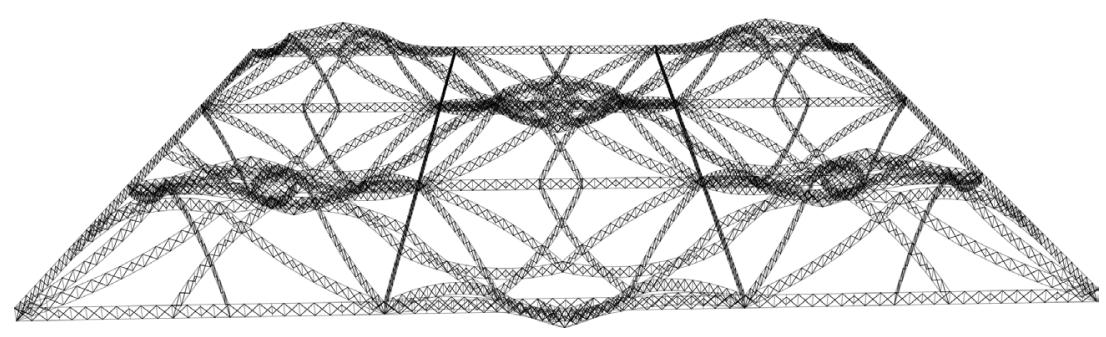

Figure 14: Replication and alternation of modules with spherical deployment.

\section{CONCLUSIONS AND FURTHER WORK}

The classification of geometry here proposed can lead to innovation, and this has been demonstrated with the design of a new type of surface with scissor 2 bar created by the concept of intersecting six lines. Also, the author has formulated a form generation method of relative ratios for scissor 2 bar: in any given combination of lines, a ratio (or various ratios) can be found as the relation between segments with respect to the number of times one is contained in the other. The author has begun to test this method with other geometries, including a curved arbitrary line that intersects itself creating a surface, and it does work. The author would like to investigate the possibility of creating a software that automates this method to any given combination of lines.

The module in the case study has been replicated to create various types of surfaces, but it could be manipulated to generate many other geometrical forms of more complex solids, lines and surfaces that would further relate to the geometry classification.

If there can be infinite combinations of lines that can be made into scissor structures with this method, and each could grow infinitely into other geometrical formations, then the subject of deployable structures, or in particular here of scissor 2 bar, appears to be related to the properties of numbers proposed by Georg Cantor's method of proof which implies the existence of an infinity of infinities, and which is the foundation of set theory.

This research has been the result of seeking a comprehensive understanding of the subject as a whole. The creation of a framework for a database that could be used by different disciplines will be investigated. Further research of how geometry explains deployable structures and articulates innovation could be critical for the future study of this fascinating field.

\section{ACKNOWLEDGEMENT}

I would like to thank John Assael of Assael Architecture and RIBA Council for his sponsorship.

\section{REFERENCES}

[1] Escrig, F., General survey of deployability in architecture. Proceeding of the 2nd International Conference on Mobile and Rapidly Assembled Structures, eds. F. Escrig \& C.A. Brebbia, Computational Mechanics Publications: Southampton, pp. 3-20, 1996.

[2] Hanaor, A. \& Levy, R., Evaluation of deployable structures for space enclosures. International Journal of Space Structures, 16(4), pp. 211-229, 2001. http://dx.doi.org/10.1260/026635101760832172

[3] Rivas Adrover, E., Deployable Structures, Laurence King Publishing: London, pp. 15-143, 2015. 
[4] Escrig, F., Valcárcel, J.P. \& Sánchez, J., Deployable cover on a swimming pool in seville. Journal of the International Association for Shell and Spatial Structures, 37(120), pp. 39-70, 1996.

[5] McLean, W. \& Silver, P., Air Structures, Laurence King Publishing: London, pp. 40-41, 2015.

[6] You, Z. \& Pellegrino, S., Cable-stiffened pantographic deployable structures Part 2: mesh reflector. AIAA Journal, 35(8), 1348-1355, 1997.

http://dx.doi.org/10.2514/2.243

[7] Escrig, F., Geometría de las Estructuras Desplegables de Aspas (Chapter 4). Arquitectura Transformable, eds. Candela, F., Pérez Piñero, E., Clatrava S., Escrig, F. \& Valcárcel, J.P., Escuela Técnica Superior de Arquitectura: Sevilla, pp. 97-124, 1993.

[8] Jensen, F. \& Pellegrino, S., Expandable "BLOB" structures. Journal of the International Association for Shell and Spatial Structures, 46(3), pp. 151-158, 2005.

[9] Sánchez-Cuenca, L., Geometric models for expandable structures. Proceeding of the 2nd International Conference on Mobile and Rapidly Assembled Structures, eds. F. Escrig \& C.A. Brebbia, Computational Mechanics Publications: Southampton, pp. 93-102, 1996.

[10] Baker, H.S., Furniture in the Ancient World. Origins and Evolution. $3100-475$ B.C, The Connoisseur: London, p. 171, 1966.

[11] Escrig, F., Las Estructuras de Emilio Pérez Piñero (Chapter 2). Arquitectura Transformable, eds. F. Candela, E. Pérez Piñero, S. Clatrava, F. Escrig \& J.P. Valcárcel, Escuela Técnica Superior de Arquitectura: Sevilla, pp. 9-32, 1993.

[12] Escrig, F., Modular, Ligero, Transformable. Un paseo por la arquitectura ligera móvil, Universidad de Sevilla, 2012.

[13] Ashby, M. \& Johnson, K., Materials and Design. The Art and Science of Material Selection in Product Design, Butterworth Heinemann: Oxford, 2002.

[14] De Temmerman, N., Design and Analysis of Deployable Bar Structures for Mobile Architectural Applications, Vrije Universiteit Brussel: Brussels, p. 76, 2007. 